\title{
C-Terminal Parathyroid Hormone Measurement
}

National Cancer Institute

\section{Source}

National Cancer Institute. C-Terminal Parathyroid Hormone Measurement. NCI

Thesaurus. Code C81964.

The determination of the amount of C-terminal parathyroid hormone present in a sample. 